\title{
Understanding antecedents of online gamers' negative emotions during the COVID-19 pandemic
}

Qiunan Zhang, University of Memphis, qzhang4@memphis.edu

Colin G. Onita, San Jose State University, colin.onita@sjsu.edu

Daniel A. Ray, University of North Alabama, dray4@una.edu

M. Shane Banks, University of North Alabama, mbanks@una.edu

Xihui Zhang, University of North Alabama,xzhang6@una.edu

\begin{abstract}
The COVID-19 pandemic resulted in millions of infections and deaths throughout the world. In such a stressful environment, people are more likely to form negative emotions that affect their behavior and mental health. During the pandemic, many people were unable to leave their homes and online gaming was a way for them to have some sense of normalcy and connect with others. Understanding the impact of playing online games on negative emotions in times of distress is a valuable research area. This study addresses the following research question: What is the impact of playing online games on gamer's negative emotions during the COVID-19 pandemic? We first investigate the stress caused by the COVID-19 pandemic, the impact of playing online games, and gamers' compensatory behaviors in such a stressful environment. We then develop a research model and a list of hypotheses to investigate the relationships among the stressors caused by the COVID-19 pandemic, playing online games, gamers' compensatory behaviors, and negative emotions. This study will advance the understanding of the impact of playing online games in such a special context and enrich the usage of compensatory behaviors by combining them and extending their use into online game behaviors. This study will also help government and industry understand the impact of online games and gamers' behaviors during the COVID-19 pandemic, and thus help them improve regulatory policies for the future.
\end{abstract}

Keywords: COVID-19 pandemic, stress, playing online games, negative emotions, compensatory behaviors

\section{Introduction}

On March 11, 2020, the World Health Organization (WHO) declared COVID-19, a disease caused by coronavirus SARS-CoV-2, a pandemic (Arden \& Chilcot, 2020). There is still great uncertainty about the scale of the disaster due to transmission of the coronavirus that causes the COVID-19 disease. We are not able to predict how many people will become infected and how many of them may die (Read et al., 2020). In such a pandemic, people more easily form negative emotions because of specific stressors. Negative emotions have proven to be one of the causes of negative behaviors (e.g., Kiefer, 2005), diseases (e.g., Smith, 2001), and other negative effects on people. People's mental health is critical during this time not only for themselves but also for society, and every possible method that can alleviate mental health problems is valuable.

Online gaming is rapidly growing (Gong et al., 2020). The world online game market is expected to have 1.3 billion users by 2025 and is projected to reach a revenue of 23.6 billion U.S. dollars in 2021 (Statista, n.d.). There are more than 2.7 billion video gamers from all over the world and about $60 \%$ of those gamers play online games. (WePC, n.d.). An online game is a video game that is either partially or primarily played 


\section{Issues in Information Systems}

Volume 22, Issue 4, pp. 21-32, 2021

through the Internet or any other available computer network (Adams, 2013). Online games are ubiquitous on modern gaming platforms, including PCs, consoles, and mobile devices, and they span many genres, including first-person shooters, strategy games, and massively multiplayer online role-playing games (MMORPGs) (Quandt \& Kröger, 2014).

There is considerable research that focuses on the impact of online gaming. Some studies indicated that playing games leads to negative emotions and behaviors such as addiction (Gentile et al., 2009; Zhan \& Chan, 2012), depression (e.g., Wei et al., 2012;), problematic behavior (Gong et al., 2020; Stetina et al., 2011), and aggression (Ferguson, 2007; Gentile et al., 2009). In contrast, other studies suggest that playing games is beneficial for gamers' cognition, emotion, and so on (e.g., Granic et al., 2014). Although there is debate about their impact, some video games are used as a treatment for certain psychological symptoms, such as attention deficit hyperactivity disorder (ADHD) (Thomas \& Woodyatt, 2020).

Traditional research has failed to focus on the impact of online games on people in especially stressful situations such as the COVID-19 pandemic. This research gap is an opportunity to investigate phenomena related to psychological health and IT in a special context. Thus, we formulate our research question as follows: What is the impact of playing online games on gamers' negative emotions during the COVID-19 pandemic? We believe this research can benefit governments, online game service providers, and IS researchers. Research on unique contexts is valuable in that we can apply what we learn to help solve similar future problems. During this pandemic, every possible method that may be beneficial to society is worthy of being investigated. This research may provide ideas and suggestions for government policy, and for online game service providers and companies to better design and manage online games and online game communities. We also hope our research can contribute some theoretical insights on special environment research in the IS field.

\section{Literature review}

To investigate the influence of the COVID-19 pandemic and the impact of games on gamers' behavior, three literature streams are reviewed: the psychological impact of a pandemic, the impact of games on gamers, and gamers' motivation.

\section{The negative impact of quarantine during the pandemic}

Researchers have few opportunities to study the impact of quarantine in pandemics because pandemics caused by diseases like COVID-19 are rare. Like COVID-19, the SARS outbreak in 2003 was also caused by coronaviruses. The response to these crises has been similar, but the COVID-19 pandemic has impacted many more people throughout the world. Many of the studies focused on negative emotions during the SARS epidemic are valuable for the current situation. The negative impact caused by such an outbreak can be both short term and long term. Bai et al. (2004) found that having been quarantined during an epidemic was the most predictive factor of acute stress disorder symptoms. In the same study, quarantined staff were significantly more likely to report exhaustion, detachment from others, anxiety when dealing with febrile patients, irritability, insomnia, poor concentration and indecisiveness, deteriorating work performance, and reluctance to work or an intention to cease their employment. In another study by Wu et al. (2009), people being quarantined were found to experience high levels of post-traumatic stress symptoms.

The negative impact of quarantining can last a considerable time. By comparing post-traumatic stress symptoms in parents and children who were quarantined with those who were not, Sprang and Silman (2013) found that the mean post-traumatic stress score was four times higher in children who had been quarantined than that in those who were not. Liu et al.'s (2012) study of hospital staff examined symptoms 


\section{Issues in Information Systems}

Volume 22, Issue 4, pp. 21-32, 2021

of depression three years after quarantine during the SARS epidemic and found that $9 \%$ (48 of 549) of the whole sample reported high depressive symptoms. In the group with high depressive symptoms, nearly $60 \%$ (29 of 48) had been quarantined. Three years after the SARS outbreak, alcohol abuse and other dependency symptoms were found to be positively associated in health-care workers with having been quarantined (Wu et al., 2009). After quarantine during the pandemic, many participants continued to engage in avoidance behaviors, such as minimizing direct contact with patients or not reporting to work (Brooks et al., 2020).

In summary, the extant literature shows that quarantine during a disease outbreak can have a negative impact on people's emotions and behaviors. Brooks et al. (2020) found that duration of isolation and quarantine, fear of infection, frustration and boredom, inadequate supplies, and inadequate information can be stressors that negatively impact emotions. Even after an outbreak is over, post-epidemic stressors, such as financial loss and stigma from others still negatively impact people's emotions.

\section{The impact of games on gamers}

There are many studies that focus on the impact of games on gamers. Indeed, research has already been conducted for decades on negative effects of gaming, including addiction (Gentile et al., 2009; Zhan \& Chan, 2012), depression (e.g., Wei et al., 2012;), problematic behavior (Gong et al., 2020; Stetina et al., 2011), and aggression (Anderson et al., 2010; Ferguson, 2007;). However, struggles to exactly identify what the effects of video games are, just as it struggles to exactly identify what the effects of food are (Bavelier et al., 2011).

There is some evidence that depressive symptoms and other related problems, rather than gaming itself, cause excessive and problematic gaming behaviors. In line with that argument, several studies reported elevations in mood, relaxation, and reduced anxiety with gameplay (Russoniello et al., 2009; Ryan et al., 2006). It has further been suggested that some of the most intense positive emotional experiences are triggered in the context of playing video games, such as pride and engagement, which are linked to a host of positive outcomes, such as well-being and positive emotions (Granic et al., 2014).

Some studies also indicate that specific types of video games seem to enhance a suite of cognitive functions, some of which appear to generalize to real-world contexts (Granic et al., 2014). For example, playing firstperson shooter video games promotes a wide range of cognitive skills such as spatial skills (Green \& Bavelier, 2012; Wai et al., 2010), and playing MMORPGs improves problem-solving skills (Prensky, 2012) and enhances creativity (Jackson et al., 2012). Additionally, computer gameplay seems to have significant social benefits. Evidence from longitudinal and experimental studies shows that playing prosocial games that reward cooperation is related to prosocial behaviors in people's daily life (Gentile et al., 2009). Despite the widespread prejudice, players who play violent games that involve cooperative play are more likely to exhibit helpful behavior both in the game and in real-life (Ferguson \& Garza, 2011). Similarly, playing cooperative violent computer games decreases the player's access to aggressive cognitions (Schmierbach, 2010). From a motivational perspective, although playing games is often considered a frivolous pastime, gaming environments may cultivate a persistent, optimistic motivational cognitive behavior and lifestyle (Granic et al., 2014).

\section{Online gamer motivation}

Understanding why people want to play online games is critical to understanding online games' impact on people's emotions. Yee (2006) summarized ten motivation subcomponents and grouped them into three overarching components (achievement, social, and immersion). The achievement component has three 


\section{Issues in Information Systems}

Volume 22, Issue 4, pp. 21-32, 2021

subcomponents: advancement (the desire to gain power, progress rapidly, and accumulate in-game symbols of wealth or status), mechanics (having an interest in analyzing the underlying rules and systems to optimize character performance), and competition (the desire to challenge and compete with others). The social component also has three subcomponents: socializing (having an interest in helping and chatting with other players), relationship (the desire to form long-term, meaningful relationships with others), and teamwork (deriving satisfaction from being part of a group effort). The immersion component has four subcomponents: discovery (finding and knowing things that most other players do not know about), roleplaying (creating a person with a background story and interacting with other players to create an improvised story), customization (having an interest in customizing the appearance and skillset of their character), and escapism (using the online environment to avoid thinking about real-life problems).

The extant literature about quarantine and isolation in a pandemic suggests the stressors mentioned at the beginning of the paper mainly contribute to the formation of negative emotions. Investigating how to reduce negative emotions and minimize the consequence of negative emotions is imperative for both individuals and the society. Many studies focus on the impact of playing video games on people. Although there are disputes among these studies concerning the impact of games, we must conclude that games impact people's emotions and behaviors. Also, gamers' motivation can help us understand what gamers expect to get from playing games. Notably, most studies about games and gamers were conducted during the prepandemic period. Therefore, the impact of games may be different during a pandemic like COVID-19 because stressors emerge naturally during the pandemic. In short, there is a research gap and a great opportunity for us to study the impact of playing games during the pandemic.

\section{Theoretical development}

Video games are interactive; players cannot passively surrender to a game's storyline. Instead, video games are designed for players to engage with their systems actively and for these systems, in turn, to react to players' agentive behaviors. There are millions of video games with vastly different themes and goals. These games can be played cooperatively or competitively, alone, with other physically present players, or with thousands of other online players. They are played on various devices, from consoles (e.g., Nintendo Wii, PlayStation), to personal computers, to cell phones. Online games are video games that are either partially or primarily played through the Internet or other computer networks (Adams, 2013).

We define gamers as individuals who regularly play video games, typically more than one hour every day (Granic et al., 2014). Gamers who play online games could play and communicate with other gamers in games through the game's internal communication functionality.

\section{The impact of the COVID-19 pandemic}

Past literature about quarantine and isolation during epidemics shows that such quarantine and isolation mainly contribute to negative emotions (Bai et al., 2004; Brooks et al., 2020; Liu et al., 2012; Sprang \& Silma, 2013; Wu et al., 2009). The COVID-19 pandemic caused similar stressors as those during the SARS outbreak. Thus, it seems likely people's (including gamers) negative emotions will be increased under stressors caused by the COVID-19 pandemic, especially as the pandemic continues for an extended period. Therefore, we develop the following hypothesis:

H1: The stress caused by the COVID-19 pandemic increases gamers' negative emotions. 


\section{Issues in Information Systems}

Volume 22, Issue 4, pp. 21-32, 2021

\section{The impact of playing online games}

To "play a game" can be regarded as two parts: play and game. Various theories were proposed to explain the possible adaptive function of play, but all fall into three major categories: play as physical training, play as social training, and play as cognitive training (Chick, 2001). These theories suggest that playful behavior displayed in early life serves to train and mature the neural and physiological correlations of adult behaviors and skills essential to survival and reproductive success. On the other hand, growing evidence from laboratory and long-term field studies supports the notion that play has an adaptive value. Gottman's (1986) research has shown the function of traditional play. The pretend context of video games may be real enough to practice controlling or modulating negative emotions in the service of those goals. Adaptive regulation strategies such as acceptance, problem-solving, and reappraisal have repeatedly been linked to less negative affect, more social support, and lower levels of depressive symptoms (Aldao et al., 2010). These same adaptive regulation strategies seem to be rewarded in gaming contexts because their use is concretely and clearly linked to goal achievement. Thus, game playing may promote the ability to reappraise emotional experiences flexibly and efficiently, teaching players the benefits of dealing with frustration and anxiety in adaptive ways.

Seligman (2011) proposed the P.E.R.M.A. model as a part of his well-being theory. The P.E.R.M.A. model describes five universal categories of experiences that constitute the foundations of a "good" and fulfilling life. These categories are as follows (Seligman, 2011):

- Positive emotions refer to a wide range of positive feelings such as excitement, joy, happiness, pride, and satisfaction.

- Engagement or flow is the state of being involved and immersed in an activity of interest.

- Relationships refer to our social interactions with other people. Not only romantic relations, but also any kind of bond that we share with other individuals or social groups fall under this category.

- Meaning is the feeling of belonging to something bigger and having a satisfactory answer to the question "Why." Meaning is both the source and result of having a purpose in life.

- Accomplishments are our life goals, including the pursuit of mastery and success.

If we follow Yee's (2006) perspective on gamer motivation for online games and their close relation to P.E.R.M.A., then we can conclude that online games offer gamers the means to act freely and safely upon their motivations in a medium that is inherently rigged to please (unlike real life). Successful online games always provide gamers the right amount of uncertainty (such as in-game tasks with rewards at stake), opportunities for social relation interactions (gamers can play and interact with different people and experience shared goals in addition to participating in a social service network), and also challenges. Gamers need to devote some effort to achieve fulfillment. Online games thus give gamers the P.E.R.M.A. experiences that include positive emotions and a "better" life. Positive emotions help undo the detrimental and de-motivating results of negative emotions (Fredrickson, 2001). Therefore, playing online games could generate positive emotions and help reduce negative emotions and thereby eliminate the negative consequences of these emotions.

During the COVID-19 pandemic, people need to follow government instructions to stop or slow the spread of the virus: keep social distance, not gather in public areas or homes, stay at home, self-isolate/selfquarantine, or quarantine. Based on prior studies on quarantine consequences (e.g., during the SARS epidemic), the entire society is likely experiencing negative disruption during the current pandemic even though not all people are asked to quarantine. Brooks et al. (2020) suggest several actions that can mitigate the consequences of quarantine during the pandemic: 


\section{Issues in Information Systems}

Volume 22, Issue 4, pp. 21-32, 2021

- Keep it as short as possible.

- Give people as much information as possible.

- $\quad$ Provide adequate supplies.

- Reduce the boredom and improve communication.

- Give health-care workers special attention.

- Apply altruism instead of compulsion.

Based on online game features and online gamer motivations, playing online games is a way to reduce stressors including fear of infection (online, not face to face), frustration, and boredom (game features); as such, playing online games could reduce boredom and improve communication. Thus, playing online games can be regarded as a potential method to mitigate quarantine consequences (e.g., negative emotions) during the pandemic. Therefore, we propose hypothesis 2 as follows:

\section{H2: Playing online games reduces gamers' negative emotions during the COVID-19 pandemic.}

\section{The impact of gamers' compensatory behavior while playing online games}

Under the pandemic restrictions and rules, people may show "compensatory behaviors." The theory of risk compensation is a behavioral theory that hypothesizes that individuals tend to compensate for changes in a risk environment (Peltzman, 1975; Viscusi, 1984). According to this theory, individuals are expected to increase their safety efforts in response to exogenous increases in risk and, conversely, decrease their safety efforts in response to decreases in risk (Rodgers, 1996). Compensatory behaviors are studied widely in sports science, food habits, psychology, management, and economics fields (e.g., Li et al., 2001; Peltzman, 1975; Rodgers, 1996; Wichman et al., 2014). Compensatory behaviors are behaviors to respond to some threats or stressors (Binford \& Le Grange, 2005). Several studies (e.g., Binford \& Le Grange, 2005; Frayn et al., 2018) indicate that compensatory behaviors are responses to negative emotions. Through such behaviors, people could relieve negative emotions such as anxiety and anger. For example, some people tend to eat and consume more calories than needed in order to relieve anxiety. Recent studies indicate that when people face uncertain threats, they show compensatory behaviors (Wichman et al., 2014). Consequently, they may undertake "compensatory behaviors" to relieve their pandemic-related negative emotions.

Rational choice theory suggests that criminal offenders respond selectively to particular situations based on the probability of being apprehended, the benefit they will reap from the crime, and the opportunity cost of selecting one option over another (Clarke \& Cornish, 1985). In the context of online games, and based on the rational choice theory, gamers may show compensatory behaviors in virtual environments under the COVID-19 pandemic. They may be more willing to exhibit "compensatory behaviors" such as aggressive behaviors, cheating, breaking game rules, impolite behaviors, and other "unusual" behaviors when they play games to relieve negative emotions. For the gamers who show such behaviors, blame from other gamers and punishment from online game providers are less costly than other costs such as the risk of infection and reputation loss. Based on the above arguments, we develop the following two hypotheses:

H3: The stress caused by the COVID-19 pandemic increases gamers' compensatory behaviors in online games.

H4: Gamers' compensatory behaviors in online games reduce gamers' negative emotions during the COVID-19 pandemic. 


\section{Issues in Information Systems}

Volume 22, Issue 4, pp. 21-32, 2021

Based on the arguments and hypotheses developed above, the proposed research model is shown in Figure 1 below.

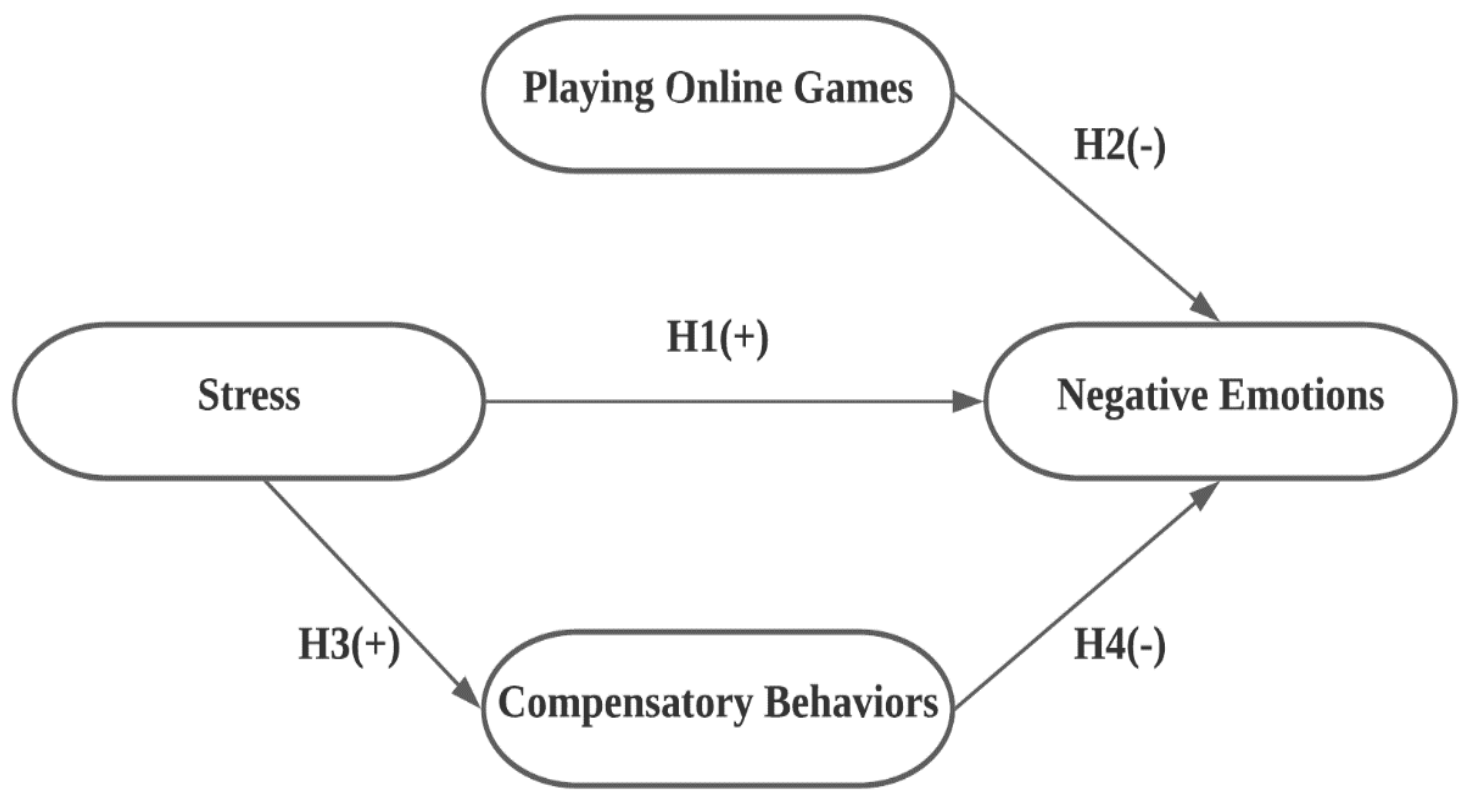

Figure 1: The Proposed Research Model

\section{Methodology}

\section{Data collection and procedure}

For this research, we plan to use an online questionnaire survey to collect data. The survey will consist of four areas of investigation: the demographic characteristics of gamers (gender, age, education, previous game experiences, types of online games, and so on), measurements of pandemic-related stress (pandemic time length, quarantine and isolation time length, etc.), data about gaming behavior (such as frequency of playing online games, time spent on playing online games, frequency of aggressive/cheating/rule-breaking behaviors when playing games), and data about negative emotions (anxiety, anger, depression). To investigate the relationship between playing online games and compensatory behaviors with negative emotions respectively, the survey will be administered multiple times to the same group of people every other week. Also, some external environment factors such as the pandemic situation, protests, and other social events should also be considered.

\section{Variables and measurements}

As mentioned above, the situation of playing online games consists of length and frequency of playing, as well as frequency of aggressive/cheating/rule-breaking behaviors. Negative emotions will be assessed in threat and harm-related emotion scales proposed by Folkman and Lazarus (1985). Based on the previous research (e.g., Brooks et al., 2020; Liu et al., 2012; Wu et al., 2009), stress from the pandemic will be measured in pandemic, quarantine, and isolation duration. Except for stress from the pandemic, all of the 


\section{Issues in Information Systems}

Volume 22, Issue 4, pp. 21-32, 2021

above variables will be measured at baseline, pre-gameplay, and post-gameplay using a seven-point Likert scale $(0=$ not at all; $6=$ extremely). Emotion scores will be averaged across each sub-scale, with a higher score indicating a higher emotion level. Control variables such as gender, age, education, previous game experience, types of online games, monthly income, and marriage status will also be collected in the survey.

\section{Discussion}

\section{Theoretical contributions}

First, our study advances the understanding of the impact of playing online games in a specific context, a pandemic environment. As we mentioned above, current studies focus on the impact of playing video games during the normal setting. Because of the pandemic, government regulations and social experiences may change people's emotional status and induce different needs from ordinary times. Consequently, playing online games may have a different effect on people's emotions. Thus, the investigation of the impact of playing online games on people's behaviors within such context may add new knowledge in the IS field.

Second, this study may enrich the usage of compensatory behaviors and the rational choice theory by combining them and extending their use into online game behaviors during a pandemic.

\section{Practical contributions}

Our findings may help government and industry understand the impact of online games and gamers' behaviors during the COVID-19 pandemic. The findings may help improve policies now or when we encounter similar situations in the future. For the game industry, our findings may help them design games and improve game management and regulations, such as enabling more social components in the game, motivation for discounting and otherwise promoting online games, and lighter punishment of inappropriate behavior during a pandemic. We expect our findings to help in advancing the understanding of the impact of online games. We also hope that our findings will help improve our society and the IS-related industry during this COVID-19 pandemic.

\section{Limitations and future research}

Our research has some limitations. A gamer's family situation may influence their emotions and compensatory behavior during the pandemic. The atmosphere of family and relationships among family members may influence gamers' psychological status. It is difficult to measure and distinguish such impacts in our research. Furthermore, a gamer's social status may also impact their emotions and behaviors. Therefore, future research should consider a gamer's family condition and social status. 


\section{Issues in Information Systems}

Volume 22, Issue 4, pp. 21-32, 2021

\section{References}

Adams, E. (2013). Fundamentals of game design ( $3^{\text {rd }}$ ed.). Thousand Oaks, CA: New Riders.

Aldao, A., Nolen-Hoeksema, S., \& Schweizer, S. (2010). Emotion-regulation strategies across psychopathology: A meta-analytic review. Clinical Psychology Review, 30(2), 217-237.

Arden, M. A., \& Chilcot, J. (2020). Health psychology and the coronavirus (COVID-19) global pandemic: A call for research. British Journal of Health Psychology, 25(2), 231-232.

Bai, Y., Lin, C.-C., Lin, C.-Y., Chen, J.-Y., Chue, C.-M., \& Chou, P. (2004). Survey of stress reactions among health care workers involved with the SARS outbreak. Psychiatric Services, 55(9), $1055-$ 1057.

Bavelier, D., Green, C. S., Han, D. H., Renshaw, P. F., Merzenich, M. M., \& Gentile, D. A. (2011). Brains on video games. Nature Reviews Neuroscience, 12, 763-768.

Binford, R. B., \& Le Grange, D. (2005). Adolescents with bulimia nervosa and eating disorder not otherwise specified purging only. International Journal of Eating Disorder, 38(2), 157-161.

Brooks, S. K., Webster, R. K., Smith, L. E., Woodland, L., Wessely, S., Greenberg, N., \& Rubin, G. J. (2020). The psychological impact of quarantine and how to reduce it: Rapid review of the evidence. The Lancet, 395(10227), 912-920.

Chick, G. (2001). What is play for? Sexual selection and the evolution of play. Play \& Culture Study, 3(1), $3-25$.

Clarke, R. V., \& Cornish, D. B. (1985). Modeling offenders' decisions: A framework for research and policy. Crime and Justice, 6, 147-185.

Ferguson, C. J. (2007). The good, the bad and the ugly: A meta-analytic review of positive and negative effects of violent video games. Psychiatric Quarterly, 78, 309-316.

Ferguson, C. J., \& Garza, A. (2011). Call of (civic) duty: Action games and civic behavior in a large sample of youth. Computers in Human Behavior, 27(2), 770-775.

Folkman, S., \& Lazarus, R. S. (1985). If it changes it must be a process: Study of emotion and coping during three stages of a college examination. Journal of Personality and Social Psychology, 48(1), 150170 .

Frayn, M., Livshits, S., \& Knäuper, B. (2018). Emotional eating and weight regulation: A qualitative study of compensatory behaviors and concerns. Journal of Eating Disorders, 6(23), 1-10.

Fredrickson, B. L. (2001). The role of positive emotions in positive psychology: The broaden-and-build theory of positive emotions. American Psychologist, 56(3), 218-226. 


\section{Issues in Information Systems}

Volume 22, Issue 4, pp. 21-32, 2021

Gentile, D. A., Anderson, C. A., Yukawa, S., Ihori, N., Saleem, M., Ming, L. K., Shibuya, A., Liau, A. K., Khoo, A., Bushman, B. J., Huesmann, L. R., \& Sakamoto, A. (2009). The effects of prosocial video games on prosocial behaviors: International evidence from correlational, longitudinal, and experimental studies. Personality and Social Psychology Bulletin, 35(6), 752-763.

Gong, X., Chen, C., \& Lee. M. K. O. (2020). What drives problematic online gaming? The role of IT identity, maladaptive cognitions, and maladaptive emotions. Computers in Human Behavior, 110(106386).

Gottman, J. M. (1986). The world of coordinated play: Same- and cross-sex friendship in young children. Cambridge, England: Cambridge University Press.

Granic, I., Lobel, A., \& Engels, R. C. M. E. (2014) The benefits of playing video games. American Psychologist, 69(1), 66-78.

Green, C. S., \& Bavelier, D. (2012). Learning, attentional control, and action video games. Current Biology, 22(6), 197-206.

Jackson, L. A., Witt, E. A., Games, A. I., Fitzgerald, H. E., von Eye, A., \& Zhao, Y. (2012). Information technology use and creativity: Findings from the Children and Technology Project. Computers in Human Behavior, 28(2), 370-376.

Kiefer, T. (2005). Feeling bad: Antecedents and consequences of negative emotions in ongoing change. Journal of Organizational Behavior, 26(8), 875-897.

Li, K. Z., Lindenberger, U., Freund, A. M., \& Baltes, P. B. (2001). Walking while memorizing: Age-related differences in compensatory behavior. Psychological science, 12(3), 230-237.

Liu, X., Kakade, M., Fuller, C. J., Fan, B., Fang, Y., Kong, J., Guan, Z., Wu, P. (2012). Depression after exposure to stressful events: Lessons learned from the severe acute respiratory syndrome epidemic. Comprehensive Psychiatry, 53(1), 15-23.

Peltzman, S. (1975). The effects of automobile safety regulation. Journal of Political Economy, 83(4), 677726.

Prensky, M. R. (2012). From digital natives to digital wisdom: Hopeful essays for 21st century learning. Thousand Oaks, CA: Corwin Press.

Quandt, T., \& Kröger, S. (2014). Multiplayer: The social aspects of digital gaming. London: Routledge.

Read, J. M., Bridgen, J. R. E., Cummings, D. A. T., Ho, A., \& Jewell, C. P. (2020). Novel coronavirus 2019-nCoV: Early estimation of epidemiological parameters and epidemic predictions. [Preprint] medRxiv.

Rodgers, B. G. (1996). Bicyclist risks and helmet usage patterns: An analysis of compensatory behavior in a risky recreational activity. Managerial and Decision Economics, 17(5), 493-507. 


\section{Issues in Information Systems}

Volume 22, Issue 4, pp. 21-32, 2021

Russoniello, C. V., O'Brien, K., \& Parks, J. M. (2009). EEG, HRV and psychological correlates while playing Bejeweled II: A randomized controlled study. Studies in Health Technology Informatics, 144(1), 189-192.

Ryan, R. M., Rigby, C. S., \& Przybylski, A. (2006). The motivational pull of video games: A selfdetermination theory approach. Motivation and Emotion, 30(4), 347-363.

Schmierbach, M. (2010). "Killing spree": Exploring the connection between competitive game play and aggressive cognition. Communication Research, 37(2), 256-274.

Seligman, M. E. P. (2011). Flourish: A visionary new understanding of happiness and well-being. New York, NY: Free Press.

Smith, D. F. (2001). Negative emotions and coronary heart disease: Causally related or merely coexistent? A review. Scandinavian Journal of Psychology, 42(1), 57-69.

Sprang, G., \& Silman, M. (2013). Posttraumatic stress disorder in parents and youth after health-related disasters. Disaster Medicine and Public Health Preparedness, 7(1), 105-110.

Statista. (n.d.). Online games worldwide. https://www.statista.com/outlook/212/100/onlinegames/worldwide

Stetina, B. U., Kothgassner, O. D., Lehenbauer, M., \& Kryspin-Exner, I. (2011). Beyond the fascination of online-games: Probing addictive behavior and depression in the world of online-gaming. Computers in Human Behavior, 27(1), 473-479.

Thomas, N., \& Woodyatt, A. (2020, June 16). Children with ADHD can now be prescribed a video game, FDA says. https:/www.cnn.com/2020/06/16/health/adhd-fda-game-intl-scli-wellness/index.html

Viscusi, W. K. (1984). The lulling effect: The impact of child-resistant packaging on aspirin and analgesic ingestions. American Economic Review, 74(2), 323-327.

Wai, J., Lubinski, D., Benbow, C. P., \& Steiger, J. H. (2010). Accomplishment in science, technology, engineering, and mathematics (STEM) and its relation to STEM educational dose: A 25-year longitudinal study. Journal of Educational Psychology, 102(4), 860-871.

Wei, H.-T., Chen, M.-H., Huang, P.-C., Bai, Y.-M. (2012). The association between online gaming, social phobia, and depression: An internet survey. BMC Psychiatry, 12(92), 1-7.

WePC. (n.d.) Video game industry statistics in 2020. https://www.wepc.com/news/video-game-statistics/

Wichman, A. L., Brunner, R. P., \& Weary, G. (2014). Uncertainty threat and inhibition of compensatory behaviors: A goal conflict management perspective. Self and Identity, 13(2), 178-196.

Wu, P., Fang, Y., Guan, Z., Fan, B., Kong, J., Yao, Z., Liu, X., Fuller, C. J., Susser, E., Lu, J., \& Hoven, C. W. (2009). The psychological impact of the SARS epidemic on hospital employees in China: Exposure, risk perception, and altruistic acceptance of risk. Canadian Journal of Psychiatry, 54(5), 302-311. 


\section{Issues in Information Systems}

Volume 22, Issue 4, pp. 21-32, 2021

Yee, N. (2006). Motivations for play in online games. CyberPsychology \& Behavior, 9(6), 772-775.

Zhan, J. D., \& Chan, H. C. (2012). Government regulation of online game addiction. Communications of the Association for Information Systems, 30, 187-198. 